\title{
EFeito de Herbicidas Aplicados em Solo de Várzea sobre a Cultura do Girassol ${ }^{1}$
}

\author{
Effect of Herbicides Applied on Sunflower Crop in Wetland Soil
}

ERASMO, E.A.L. ${ }^{2}$, COSTA, N.V. ${ }^{3}$, PERUZZO, A.S. ${ }^{4}$ e BARBERATO JUNIOR, J.E. ${ }^{4}$

\begin{abstract}
RESUMO - Objetivou-se neste trabalho avaliar em solos de várzea o efeito de herbicidas préemergentes, aplicados isoladamente e em mistura, sobre a cultura do girassol. A variedade de girassol Embrapa V122 e o híbrido triplo Agrobel 972 foram avaliados individualmente, utilizando-se o delineamento experimental de blocos casualizados, com quatro repetições. Foram realizados dois experimentos, e os tratamentos utilizados em ambos foram: oxadiazon $\left(250 \mathrm{~g} \mathrm{ha}^{-1}\right)$, oxyfluorfen $\left(240 \mathrm{~g} \mathrm{ha}^{-1}\right)$, S-metolachlor $\left(1.440 \mathrm{~g} \mathrm{ha}^{-1}\right)$, flumetsulam $\left(120 \mathrm{~g} \mathrm{ha}^{-1}\right)$, pendimethalin $\left(1.000 \mathrm{~g} \mathrm{ha}^{-1}\right)$, oxyfluorfen $+\mathrm{S}$-metolachlor $\left(192+960 \mathrm{~g} \mathrm{ha}^{-1}\right)$, flumetsulam $+\mathrm{S}$-metolachlor $\left(72+960 \mathrm{~g} \mathrm{ha}^{-1}\right)$, pendimethalin $+\mathrm{S}$-metolachlor $\left(1.000+1.440 \mathrm{~g} \mathrm{ha}^{-1}\right)$, pendimethalin+flumetsulam $\left(1.000+72 \mathrm{~g} \mathrm{ha}^{-1}\right)$, além de duas testemunhas, sem e com capina. Os dados de altura de planta, diâmetro do caule, diâmetro do capitulo e da produção de grãos foram submetidos aos testes estatísticos multivariados de análise de agrupamento e análise de componentes principais. Os resultados foram semelhantes em ambos os cultivares, com a formação de três grupos principais, sendo o primeiro e o segundo constituídos pelas testemunhas sem e com capina, respectivamente. O terceiro grupo foi constituído pelos herbicidas aplicados isoladamente e em mistura. Dessa forma, verificou-se que os efeitos causados pelos herbicidas aplicados isoladamente e em mistura sobre as variáveis analisadas foram menos prejudiciais em relação aos da interferência das plantas daninhas. Esses resultados evidenciaram potencial de seletividade dos herbicidas aplicados isoladamente e em mistura na variedade de girassol Embrapa V122 e no híbrido triplo Agrobel 972, nas condições em que foram avaliados.
\end{abstract}

Palavras-chave: análise multivariada, Helianthus annuиs, mistura em tanque, planta daninha, seletividade.

\begin{abstract}
This study aimed to evaluate the effect of applying different pre-emergent herbicides, alone and in combination, on sunflower crop in wetland soil. The sunflower variety Embrapa V122 and the triple hybrid Agrobel 972 were evaluated individually using a randomized block design with four replications. Two experiments were conducted, with the following treatments being

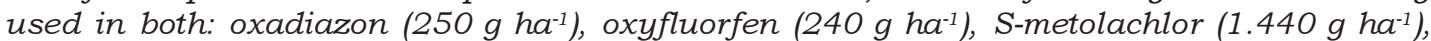
flumetsulam (120 g ha-1), pendimethalin (1.000 $\mathrm{g} \mathrm{ha}-1$ ), oxyfluorfen+S-metolachlor (192+960 $\mathrm{g} \mathrm{ha}-1$ ), flumetsulam+S metolachlor $\left(72+960 \mathrm{~g} \mathrm{ha}^{-1}\right)$, pendimethalin+S-metolachlor $\left(1.000+1.440 \mathrm{~g} \mathrm{ha}^{-1}\right)$, pendimethalin + flumetsulam $\left(1.000+72 \mathrm{~g} \mathrm{ha}^{-1}\right)$, and two controls, with and without weeding. Plant height, stem diameter, chapter and grain yield diameter were submitted to statistical multivariate tests of cluster analysis and Principal Components Analysis. The results were similar in both cultivars evaluated, showing the formation of three main groups. with the first and second groups consisting of the controls with and without weeding, respectively. The third group was composed of the herbicides applied alone and in combination. The effects caused by the herbicides applied alone and in combination on the variables analyzed were found to be less harmful than the effects of weed interference. These results show the potential for selectivity of the herbicides applied alone and in combination on the sunflower variety Embrapa V122 and on the triple hybrid Agrobel 972, under the evaluated conditions.
\end{abstract}

Keywords: multivariate analysis, Helianthus annuus, tank mixture, weed, selectivity.

1 Recebido para publicação em 27.10.2009 e na forma revisada em 12.11.2010.

2 Professor Adjunto, Universidade Federal do Tocantins - UFT, Rua Badejós, Chácaras 69 e 72, Lt.07, Zona Rural, Caixa Postal 66, 77404-970 Gurupi-TO; ${ }^{3}$ Professor Adjunto, UNIOESTE/CCA, Marechal Cândido Rondon-PR <neumarciovc@hotmail.com>; ${ }^{4}$ Graduando de Agronomia, UFT, campus de Gurupi-TO. 


\section{INTRODUÇÃO}

O girassol (Helianthus annuus) destaca-se entre as espécies vegetais de maior potencial para a produção de biocombustivel no Brasil, além de ser alternativa importante em sistemas que envolvem rotação de culturas. Devido às características de resistência à seca e à baixa temperatura, o girassol apresenta ampla adaptabilidade a diferentes regiões agrícolas, propiciando a expansão de sua área cultivada em diversas regiões do País (Brighenti et al., 2004; Castro \& Farias, 2005).

O Estado do Tocantins apresenta condições edafoclimáticas favoráveis à exploração agrícola da cultura do girassol, a exemplo das áreas de várzeas do Projeto Rio Formoso, no município de Formoso do Araguaia, e do Projeto Javaés, na Lagoa da Confusão, que utilizam irrigação por subinundação, a qual consiste no sistema de tabuleiros com canais utilizados para elevar o nível do lençol freático (Pelúzio et al., 2008). Esse sistema de irrigação viabiliza a safra do arroz irrigado no período das chuvas e na entressafra e o cultivo de espécies de sequeiro, como o girassol.

Entretanto, como toda cultura, o girassol está sujeito a uma série de fatores, bióticos e abióticos, que influenciam seu crescimento, desenvolvimento e a produtividade econômica. Dentre esses fatores, destaca-se a interferência causada pela convivência da cultura com as plantas daninhas, que pode resultar na perda de rendimento de aquênios e do teor de óleo em cerca de 20 a 70\% (Pitelli, 1985; Brighenti et al., 2004).

Dessa forma, o controle químico tem sido um dos métodos mais utilizados no manejo das plantas daninhas, considerando principalmente extensas áreas de cultivo, devido à maior praticidade e eficiência. Entretanto, apenas os herbicidas alachlor e trifluralin são registrados no Brasil para a cultura do girassol, o que constitui um fator limitante para o manejo das plantas daninhas nessa cultura (Rodrigues et al., 2005).

Os herbicidas oxadiazon, oxyfluorfen, S-metolachlor, flumetsulam e pendimethalin são amplamente utilizados no sistema de rotação arroz irrigado/soja nas áreas de várzea dos Projetos Rio Formoso e Javaés. Contudo, ressalta-se que esses herbicidas podem apresentar persistência relativamente longa no solo, variando de 30 a 180 dias, dependendo de fatores como a fotodecomposição, adsorção aos coloides do solo, teor de matéria orgânica no solo, lixiviação, volatilização, absorção e metabolização pelas plantas e/ou microrganismos (Vidal \& Fleck, 1994; Fleck \& Vidal, 1994; Rodrigues \& Almeida, 2005). Portanto, essa característica pode prejudicar o desenvolvimento de algumas culturas em sucessão ao arroz irrigado ou a soja em áreas de várzea.

Considerando a alternativa de rotação arroz irrigado/girassol em condições de várzea, existem poucas informações na literatura referentes à seletividade dos herbicidas oxadiazon, oxyfluorfen, S-metolachlor, flumetsulam e pendimethalin para a cultura do girassol.

Segundo Blanco \& Velini (2005), os herbicidas devem ser usados de forma técnica e criteriosa, sempre buscando maximizar as suas vantagens e minimizar os riscos toxicológicos, ambientais e a toxicidade para plantas suscetiveis utilizadas como culturas sucedâneas à cultura tratada, a exemplo dos herbicidas residuais. Outro aspecto importante refere-se à associação entre dois ou mais herbicidas, que, embora proibida por lei, tornou-se prática comum no manejo das plantas daninhas visando, principalmente, aumentar o espectro de espécies controladas e/ou o período de controle destas (Vangessel et al., 2000; Damalas \& Eleftherohorinos, 2001), além de buscar reduzir a pressão de seleção, que favorece a evolução de plantas daninhas resistentes aos herbicidas.

Dessa maneira, torna-se importante a realização de estudos referentes à seletividade de novos herbicidas para a cultura do girassol com mecanismo de ação e espectro de controle distintos, uma vez que esse recurso pode auxiliar no manejo das plantas daninhas, aumentar as opções de rodízio, misturas de herbicidas e, portanto, prevenir o aparecimento de plantas resistentes a herbicidas.

Assim, objetivou-se neste estudo avaliar, na cultura do girassol, o efeito de diferentes herbicidas pré-emergentes aplicados isoladamente ou em mistura em condições de solo de várzea. 


\section{MATERIAL E MÉTODOS}

Os experimentos foram conduzidos em campo na Área Experimental da Embrapa Arroz e Feijão, localizada no município de Formoso do Araguaia-TO, em área de várzea sistematizada.

No solo classificado como Gleissolo (Embrapa, 1999), foi feita aração e duas gradagens. A análise química apresentou as seguintes características: $\mathrm{pH}\left(\mathrm{CaCl}_{2}\right)=5,7$; matéria orgânica $\left(\mathrm{g} \mathrm{dm}^{-3}\right)=46,0 ; \mathrm{P}\left(\mathrm{mg} \mathrm{dm}^{-3}\right)=$ 21,$0 ; \mathrm{H}+\mathrm{Al}, \mathrm{K}, \mathrm{Ca}, \mathrm{Mg}$, SB e CTC $\left(\mathrm{cmolc} \mathrm{dm}^{-3}\right)=$ 7,$04 ; 105,00 ; 2,70 ; 0,57 ; 108,27$ e 115,31, respectivamente; e V\% $=93,89$, tendo em sua composição textural $70,0 \%$ de areia, $7,0 \%$ de silte e $23,0 \%$ de argila.

Foram avaliados a variedade de girassol Embrapa V122 e o híbrido triplo Agrobel 972, semeados em 10/6/2008, utilizando-se o espaçamento de 0,65 m entre linhas e 0,25 entre plantas.

De acordo com os resultado da analise química, foram aplicados $450 \mathrm{~kg} \mathrm{ha}^{-1}$ de NPK do formulado $5-30-15$, com $2 \%$ de $\mathrm{S}$ e $4 \%$ de Ca. A adubação de cobertura foi realizada 30 dias após a semeadura, utilizando 2, 56 e $90 \mathrm{~kg} \mathrm{ha}^{-1}$ de ácido bórico, $\mathrm{KCl}$ e ureia, respectivamente, distribuídos com auxílio de um carrinho adubador.

Para evitar a interferência das plantas daninhas oriundas do banco de sementes, todas as parcelas com aplicação de herbicidas foram mantidas no limpo por meio de capinas quinzenais, com exceção da testemunha sem capina.

Os materiais de girassol foram avaliados individualmente, utilizando-se o delineamento experimental de blocos casualizados com quatro repetições; cada parcela foi constituída de 3,9 × 6,0 m, apresentando área total de $23,4 \mathrm{~m}^{2}$.

Os tratamentos aplicados em cada experimento estão descritos na Tabela 1 . Os herbicidas foram aplicados logo após a semeadura dos cultivares, com um pulverizador costal pressurizado a $\mathrm{CO}_{2}$, munido de barra com quatro bicos Teejet DG 110.02VS, espaçados de 0,50 m, com pressão de serviço de 32 libras pol $^{-2}$, para obter o volume de calda de $200 \mathrm{~L} \mathrm{ha}^{1}$.
As aplicações foram realizadas com as seguintes condições climáticas: $33{ }^{\circ} \mathrm{C}$ de temperatura, $32 \%$ de umidade relativa do ar e $0,6 \mathrm{~m} \mathrm{~s}^{-1}$ de velocidade do vento. As condições do clima durante o período de condução dos experimentos estão descritas na Figura 1.

As avaliações de intoxicação das plantas de girassol foram feitas por meio visual, utilizando-se uma escala percentual de notas, em que 0 (zero) correspondeu a nenhuma injúria demonstrada pela planta e 100 à morte das plantas (SBCPD, 1995). Os parâmetros utilizados para o estabelecimento das notas foram: inibição do crescimento, quantidade e uniformidade das injúrias e quantidade de plantas mortas. As avaliações foram feitas aos 7, 14, 21 e 28 DAA (dias após a aplicação).

Foram avaliados os seguintes parâmetros: altura de planta, medindo-se a partir da inserção do capítulo até o solo; diâmetro do caule, amostrando-se 20 plantas, mensurado a $5 \mathrm{~cm}$ do nível do solo com auxílio de paquímetro; diâmetro de capítulos, medindo-se com uma régua graduada em centímetros, 30 capítulos da área útil no momento da colheita, além da produção de grãos. Os cultivares Embrapa 122 e Agrobel 972 foram colhidos aos 102 e 115 dias após a emergência das plântulas, respectivamente.

As avaliações de altura de planta, diâmetro do caule e diâmetro do capítulo foram realizadas aos 85 DAA.

Tabela 1 - Tratamentos avaliados nos experimentos com a variedade de girassol Embrapa V122 e o híbrido triplo Agrobel 972. Formoso do Araguaia-TO, 2008

\begin{tabular}{|l|c|}
\hline \multicolumn{1}{|c|}{ Tratamento } & Dose \\
\cline { 2 - 2 } & $\left(\mathrm{g} \mathrm{ha}^{-1}\right)$ \\
\hline Testemunha sem capina & $\ldots .$. \\
\hline Testemunha capinada & $\ldots$. \\
\hline oxadiazon & 250 \\
\hline oxyfluorfen & 240 \\
\hline S-metolachlor & 1.440 \\
\hline flumetsulam & 120 \\
\hline pendimethalin & 1.000 \\
\hline oxyfluorfen + S-metolachlor & $192+960$ \\
\hline flumetsulam + S-metolachlor & $72+960$ \\
\hline pendimethalin + S-metolachlor & $1.000+1.440$ \\
\hline pendimethalin + flumetsulam & $1.000+72$ \\
\hline
\end{tabular}

Planta Daninha, Viçosa-MG, v. 28, n. 4, p. 843-852, 2010 


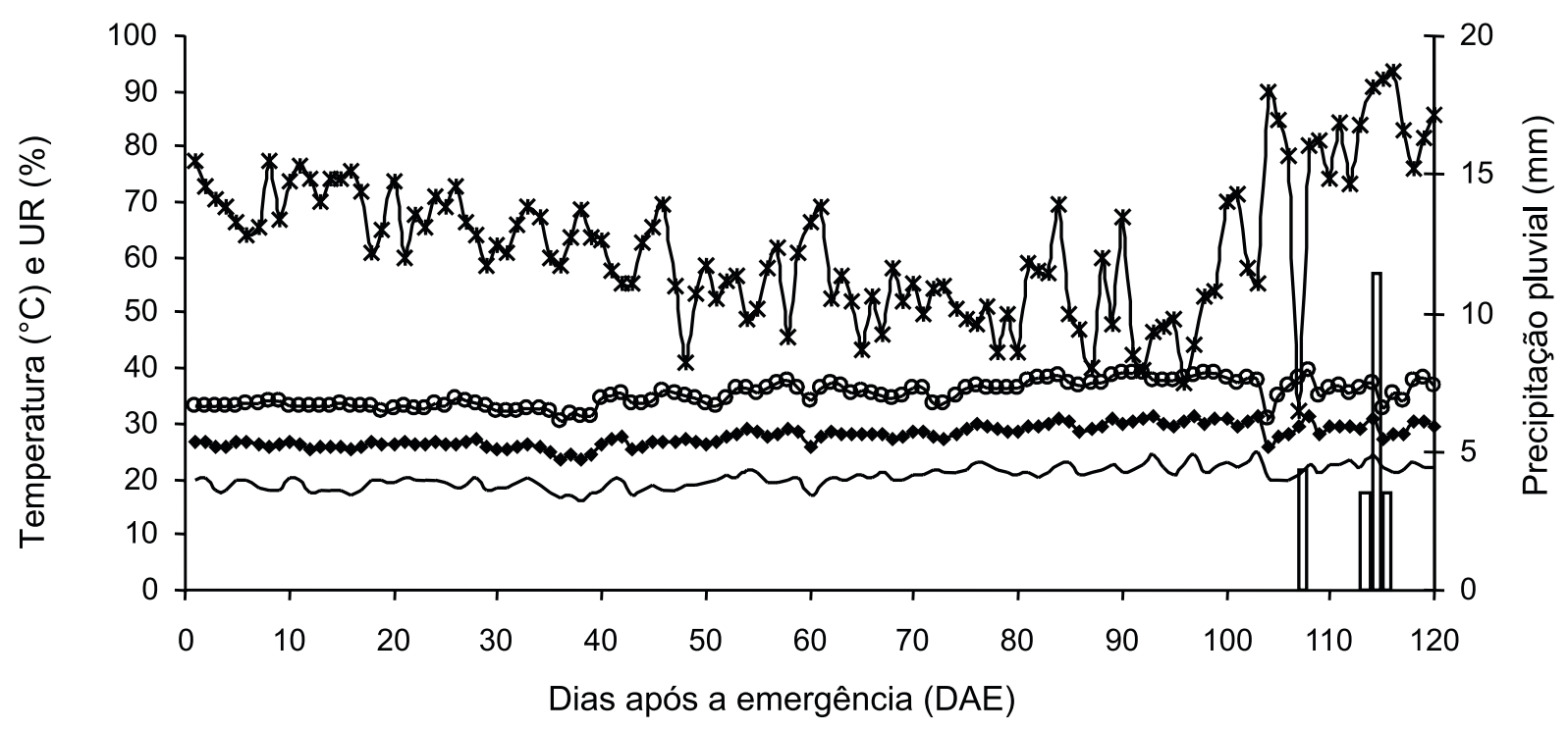

$\square$ Precipitação $\multimap$ Tmédia —Tmáxima —Tmínima * UR (\%)

Figura 1 - Condições do clima durante o período de condução dos experimentos.

Os dados obtidos foram submetidos à análise multivariada, compreendendo a análise de agrupamento e análise de componentes principais (Sneath \& Sokal, 1973).

A análise de componentes principais foi empregada para verificar a capacidade discriminatória dos caracteres originais no processo de formação dos agrupamentos, reduzindo o conjunto dos caracteres a duas novas variáveis não correlacionadas, chamadas componentes principais e indicadas por $\mathrm{Y}_{1}$ e $\mathrm{Y}_{2}$ - o resultado dessa análise foi apresentado na forma de dispersão gráfica. A análise de agrupamento foi realizada com os dados transformados, empregando-se a Distância Euclidiana Média para o conjunto dos indicadores, utilizando-se o algoritmo UPGMA (Unweighted Pair Group Method with Arithmetic Average), conforme recomendado por Rohlf (1970), com a finalidade de agrupar em cada cultivar de girassol os tratamentos de acordo com seu grau de similaridade - o resultado dessa análise foi apresentado na forma de um dendrograma.

\section{RESULTADOS E DISCUSSÃO}

As espécies de plantas daninhas presentes na área experimental foram: Cyperus sp. (tiririca), Amaranthus sp. (caruru), Portulaca oleracea (beldroega), Digitaria horizontalis (capim-colchão) e Oriza sativa (arroz voluntário). Segundo Brighenti et al. (2003), essas espécies destacam-se entre as de maior ocorrência em áreas cultivadas com a cultura do girassol.

Na Tabela 2 estão apresentadas as porcentagens de intoxicação nas plantas de girassol Embrapa V122 após aplicação de herbicidas pré-emergentes. Observou-se que apenas os herbicidas flumetsulam e pendimethalin não promoveram injúrias às plantas de girassol, independentemente dos dias após a aplicação.

Contudo, pode-se constatar que os sintomas de intoxicação provocados pelos demais tratamentos com herbicidas foram inferiores a 1,3\%, sendo considerados despreziveis. Todos esses sintomas dissiparam-se completamente aos 28 DAA.

Como o presente experimento foi conduzido em área de várzea sistematizada, a seletividade dos herbicidas pode ter sido maximizada pelas características do solo, como alto teor de matéria orgânica, e pelo sistema de irrigação por subinundação, pois os processos de complexação, adsorção e/ou o movimento ascendente da água de irrigação, provavelmente, mantiveram o posicionamento dos 
herbicidas na camada superficial do solo, impedindo o contato com a semente durante o processo de germinação e, posteriormente, com o sistema radicular (Stougaard et al., 1990; Souza et al., 1996; Procópio et al., 2001).

Os valores médios das quatro variáveis analisadas na variedade Embrapa V122, utilizadas na análise multivariada, estão descritos na Tabela 3. A análise desses resultados demonstrou que os dois primeiros componentes principais $\left(\mathrm{Y}_{1}\right.$ e $\left.\mathrm{Y}_{2}\right)$ foram responsáveis por $99,43 \%$ da informação acumulada pelas variáveis avaliadas; a ocorrência de maiores valores absolutos em $\mathrm{Y}_{1}$ e $\mathrm{Y}_{2}$ correlaciona-se com as variáveis que apresentaram maior poder discriminatório entre os tratamentos avaliados (Tabela 4).

Pode-se verificar que o primeiro componente principal $\left(\mathrm{Y}_{1}\right)$ apresentou 92,19\% de informação retida, a qual foi considerada satisfatória para explicar a contribuição das variáveis analisadas na formação dos agrupamentos dos tratamentos aplicados em Embrapa V122. Entretanto, para o segundo componente principal $\left(\mathrm{Y}_{2}\right)$, o valor da informação retida foi de apenas $7,24 \%$, o que mostrou baixa contribuição das variáveis analisadas para a discriminação dos agrupamentos formados pelos tratamentos avaliados.

Tabela 2 - Porcentagem de intoxicação em plantas de girassol Embrapa V122 após aplicação de herbicidas pré-emergentes

\begin{tabular}{|l|c|c|c|c|c|}
\hline \multirow{2}{*}{\multicolumn{1}{c|}{ Tratamento }} & Dose & \multicolumn{3}{c|}{ Dias após a aplicação (DAA) } \\
\cline { 2 - 6 } & $\left(\mathrm{g} \mathrm{ha}^{-1}\right)$ & 7 & 14 & 21 & 28 \\
\hline Testemunha sem capina & $\ldots .$. & 0,0 & 0,0 & 0,0 & 0,0 \\
\hline Testemunha capinada & $\ldots$. & 0,0 & 0,0 & 0,0 & 0,0 \\
\hline oxadiazon & 250 & 1,3 & 0,0 & 0,0 & 0,0 \\
\hline oxyfluorfen & 240 & 1,3 & 1,3 & 1,3 & 0,0 \\
\hline S-metolachlor & 1440 & 1,3 & 1,3 & 1,3 & 0,0 \\
\hline flumetsulam & 120 & 0,0 & 0,0 & 0,0 & 0,0 \\
\hline pendimethalin & 1000 & 0,0 & 0,0 & 0,0 & 0,0 \\
\hline oxyfluorfen + S-metolachlor & $192+960$ & 1,3 & 0,0 & 0,0 & 0,0 \\
\hline flumetsulam + S-metolachlor & $72+960$ & 1,3 & 1,3 & 0,0 & 0,0 \\
\hline pendimethalin + S-metolachlor & $1000+1440$ & 1,3 & 0,0 & 0,0 & 0,0 \\
\hline pendimethalin + flumetsulam & $1000+72$ & 1,3 & 1,3 & 0,0 & 0,0 \\
\hline
\end{tabular}

Tabela 3 - Valores médios das quatro variáveis analisadas na variedade Embrapa V122, utilizadas na análise multivariada

\begin{tabular}{|l|c|c|c|c|c|}
\hline \multirow{2}{*}{\multicolumn{1}{c|}{ Tratamento }} & Dose & $\begin{array}{c}\text { Altura da } \\
\text { planta }\end{array}$ & $\begin{array}{c}\text { Diâmetro do } \\
\text { caule }\end{array}$ & $\begin{array}{c}\text { Diâmetro do } \\
\text { capítulo }\end{array}$ & Produtividade \\
\cline { 2 - 6 } & $\left(\mathrm{g} \mathrm{ha}^{-1}\right)$ & $(\mathrm{cm})$ & $(\mathrm{mm})$ & $(\mathrm{cm})$ & $\left(\mathrm{kg} \mathrm{ha}^{-1}\right)$ \\
\hline Testemunha sem capina & $\ldots$. & 168,75 & 24,25 & 47,25 & $1.974,00$ \\
\hline Testemunha capinada & $\ldots$. & 185,25 & 34,50 & 67,50 & $4.059,92$ \\
\hline oxadiazon & 250 & 179,50 & 27,75 & 62,50 & $3.658,47$ \\
\hline oxyfluorfen & 240 & 178,25 & 26,75 & 61,50 & $3.465,37$ \\
\hline S-metolachlor & 1440 & 178,75 & 26,75 & 61,25 & $3.411,72$ \\
\hline flumetsulam & 120 & 175,75 & 28,25 & 62,25 & $3.372,83$ \\
\hline pendimethalin & 1000 & 180,75 & 27,75 & 63,25 & $3.656,57$ \\
\hline oxyfluorfen + S-metolachlor & $192+960$ & 174,75 & 26,00 & 60,75 & $3.236,79$ \\
\hline flumetsulam + S-metolachlor & $72+960$ & 181,25 & 29,00 & 64,50 & $3.863,80$ \\
\hline pendimethalin + S-metolachlor & $1.000+1.440$ & 174,75 & 27,00 & 60,75 & $3.443,58$ \\
\hline pendimethalin + flumetsulam & $1.000+72$ & 179,50 & 28,00 & 62,25 & $3.538,01$ \\
\hline
\end{tabular}


Tabela 4 - Coeficientes de correlação entre as quatro variáveis analisadas na variedade Embrapa V122 e os dois primeiros componentes principais

\begin{tabular}{|c|l|c|c|}
\hline $\mathrm{N}^{-}$ & \multicolumn{1}{|c|}{ Variáveis } & $\mathrm{Y}_{1}$ & $\mathrm{Y}_{2}$ \\
\hline 1 & Altura de planta $(\mathrm{cm})$ & 0,936100 & 0,112471 \\
\hline 2 & Diâmetro do caule $(\mathrm{mm})$ & 0,821460 & 0,570175 \\
\hline 3 & Diâmetro do capítulo $(\mathrm{cm})$ & 0,987526 & $-0,101066$ \\
\hline 4 & Produtividade $\left(\mathrm{kg} \mathrm{ha}^{-1}\right)$ & 0,992135 & $-0,120137$ \\
\hline & \% Informação retida & 92,19 & 7,24 \\
\hline-- & \% Informação acumulada & 92,19 & 99,43 \\
\hline
\end{tabular}

O dendrograma resultante da análise de agrupamento (Figura 2) e a dispersão gráfica referente à análise dos componentes principais (Figura 3) evidenciaram a formação de três grupos principais, determinados próximo do valor de 0,08 da escala de distância de similaridade (Figura 2).

O primeiro e o segundo grupo foram formados pelos tratamentos correspondentes às testemunhas sem e com capina, respectivamente. O terceiro grupo foi constituído pelos tratamentos de herbicidas aplicados isoladamente e em mistura.
Observando os valores médios das variáveis de maior poder discriminatório do componente principal $\mathrm{Y}_{1}$ (Tabelas 1 e 2), associados à dispersão gráfica (Figura 3), podese constatar que a testemunha sem capina, constituinte do grupo 1, apresentou os menores valores médios relativos a altura de planta, diâmetro do caule, diâmetro do capítulo e produção de grãos, em comparação às médias obtidas pelos tratamentos dos grupos 2 e 3 . Ressalta-se que os tratamentos dos grupos $2 \mathrm{e}$ 3 mostraram valores médios das variáveis similares entre si.

Na Tabela 5 são apresentadas as porcentagens de intoxicação nas plantas de girassol Agrobel 972 após aplicação de herbicidas préemergentes. Observa-se que as plantas tratadas com os herbicidas flumetsulam e com as misturas oxyfluorfen+S-metolachlor e pendimethalin+flumetsulam não apresentaram injúrias.

Entretanto, os sintomas de intoxicação causados pelos demais tratamentos foram inferiores a 3,8\% e dissiparam-se completamente aos 28 DAA, sendo considerados despreziveis - semelhantes aos efeitos observados em Embrapa V122.

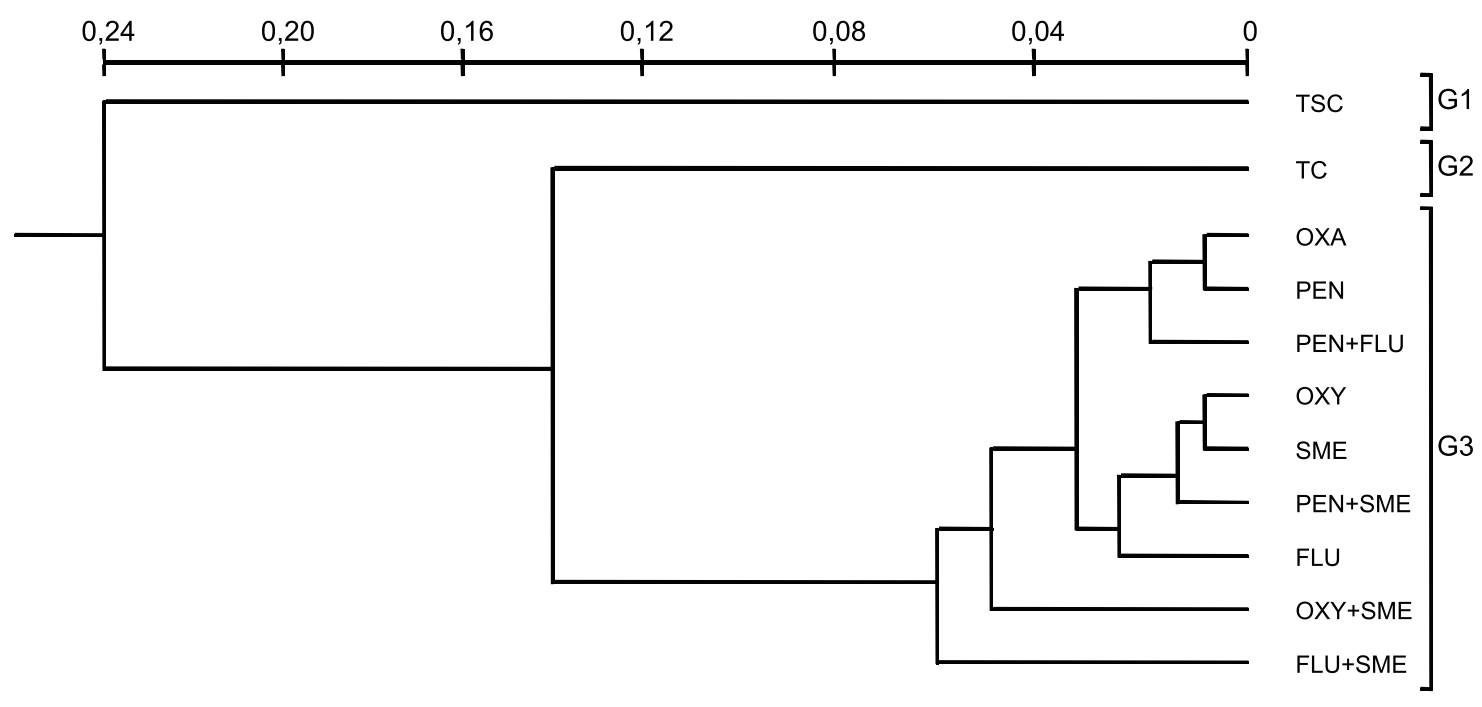

Figura 2 - Dendrograma resultante da análise de agrupamento dos tratamentos referentes à variedade Embrapa V122, utilizando-se a distância euclidiana média. $\mathrm{G} 1=$ grupo $1 ; \mathrm{G} 2=$ grupo $2 ; \mathrm{G} 3=$ grupo 3 ; TSC = testemunha sem capina; TC $=$ testemunha capinada; OXA = oxadiazon; OXY = oxyfluorfen; $\mathrm{SME}=$ S-metolachlor; FLU = flumetsulam; PEN = pendimethalin; OXY $+\mathrm{SME}$ $=$ oxyfluorfen + S-metolachlor; FLU+SME $=$ flumetsulam + S-metolachlor; PEN+SME = pendimethalin + S-metolachlor; $\mathrm{PEN}+\mathrm{FLU}=$ pendimethalin + flumetsulam . 


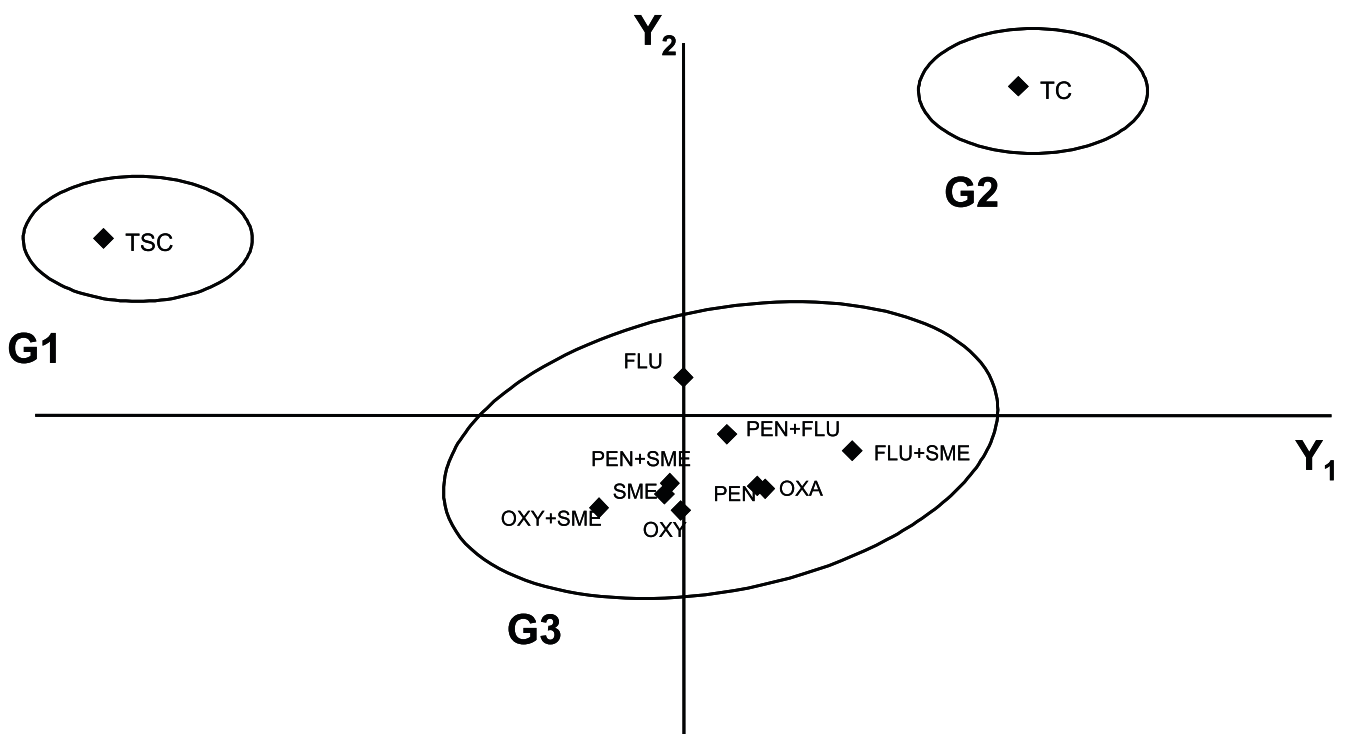

Figura 3 - Dispersão gráfica dos tratamentos referentes à variedade Embrapa V122, utilizando-se os dois primeiros componentes principais $\left(\mathrm{Y}_{1}\right.$ e $\left.\mathrm{Y}_{2}\right) \cdot \mathrm{G} 1=$ grupo $1 ; \mathrm{G} 2=$ grupo $2 ; \mathrm{G} 3=$ grupo $3 ; \mathrm{TSC}=$ testemunha sem capina; $\mathrm{TC}=$ testemunha capinada; $\mathrm{OXA}$ = oxadiazon; $\mathrm{OXY}=$ oxyfluorfen; $\mathrm{SME}=\mathrm{S}$-metolachlor; $\mathrm{FLU}=$ flumetsulam; $\mathrm{PEN}=$ pendimethalin; $\mathrm{OXY}+\mathrm{SME}=$ oxyfluorfen + S-metolachlor; FLU+SME $=$ flumetsulam + S-metolachlor; PEN+SME $=$ pendimethalin + S-metolachlor; PEN + FLU $=$ pendimethalin + flumetsulam.

Tabela 5 - Porcentagem de intoxicação de plantas de girassol Agrobel 972 após aplicação de herbicidas pré-emergentes

\begin{tabular}{|l|c|c|c|c|c|}
\hline \multirow{2}{*}{\multicolumn{1}{|c|}{ Tratamento }} & Dose & \multicolumn{3}{c|}{ Dias após a aplicação (DAA) } \\
\cline { 2 - 7 } & $\left(\mathrm{g} \mathrm{ha}^{-1}\right)$ & 7 & 14 & 21 & 28 \\
\hline Testemunha sem capina & $\ldots .$. & 0,0 & 0,0 & 0,0 & 0,0 \\
\hline Testemunha capinada & $\ldots .$. & 0,0 & 0,0 & 0,0 & 0,0 \\
\hline oxadiazon & 250 & 1,3 & 0,0 & 0,0 & 0,0 \\
\hline oxyfluorfen & 240 & 1,3 & 1,3 & 1,3 & 0,0 \\
\hline S-metolachlor & 1440 & 0,0 & 1,3 & 1,3 & 0,0 \\
\hline flumetsulam & 120 & 0,0 & 0,0 & 0,0 & 0,0 \\
\hline pendimethalin & 1000 & 1,3 & 1,3 & 1,3 & 0,0 \\
\hline oxyfluorfen + S-metolachlor & $192+960$ & 0,0 & 0,0 & 0,0 & 0,0 \\
\hline flumetsulam + S-metolachlor & $72+960$ & 3,8 & 1,3 & 1,3 & 0,0 \\
\hline pendimethalin + S-metolachlor & $1.000+1.440$ & 0,0 & 2,5 & 1,3 & 0,0 \\
\hline pendimethalin + flumetsulam & $1.000+72$ & 0,0 & 0,0 & 0,0 & 0,0 \\
\hline
\end{tabular}

Os diferentes niveis de sintomas de intoxicação observados entre os cultivares de girassol quando tratados com um mesmo herbicida corroboram o trabalho de Felipe et al. (2006), os quais demonstraram que as injúrias causadas em uma espécie por um determinado herbicida podem variar com o cultivar.

Da mesma maneira, Castro et al. (2002) observaram que o oxyfluorfen (360 $\left.\mathrm{g} \mathrm{ha}^{-1}\right)$ aplicado isoladamente ou em mistura com duas fontes de boro foi altamente seletivo à cultura do girassol Cargil 11. Contudo, Brighenti et al. $(2000 a, b)$ verificaram que a seletividade dos herbicidas metolachlor e oxyfluorfen em girassol foi dependente da dose aplicada.

Os valores médios das quatro variáveis analisadas no híbrido triplo Agrobel 972, 
utilizadas na análise multivariada, estão descritos na Tabela 6. Pode-se verificar que os dois primeiros componentes principais $\left(\mathrm{Y}_{1}\right.$ e $\mathrm{Y}_{2}$ ) foram responsáveis por $98,85 \%$ da informação acumulada pelas variáveis avaliadas (Tabela 7).

Destaca-se que a informação retida de $90,73 \%$, referente ao primeiro componente principal $\left(\mathrm{Y}_{1}\right)$, foi considerada satisfatória para explicar a contribuição das variáveis analisadas na formação dos agrupamentos dos tratamentos. Para o segundo componente principal $\left(\mathrm{Y}_{2}\right)$, o valor da informação retida foi de apenas $8,12 \%$.

De acordo com o dendrograma resultante da análise de agrupamento (Figura 4) e com a dispersão gráfica referente à análise dos componentes principais (Figura 5), pode-se constatar a formação de três grupos principais, considerando o mesmo valor $(0,08)$ da escala de distância de similaridade adotado para determinação dos grupos em Embrapa V122 (Figura 4).

Assim, o primeiro e o segundo grupo foram constituídos pelas testemunhas sem e com capina, respectivamente; o terceiro grupo foi formado pelos demais tratamentos de herbicidas avaliados.

Por meio da relação dos valores médios das variáveis analisadas de maior poder discriminatório do componente principal $Y_{1}$ (Tabelas 6 e 7), com os dados da dispersão gráfica (Figura 5), verificou-se que a testemunha sem capina, pertencente ao grupo 1, apresentou os menores valores médios relativos a altura de planta, diâmetro do caule, diâmetro do capítulo e produção de grãos, em comparação às médias obtidas pelos tratamentos dos grupos 2 e 3 , os quais mostraram valores médios das variáveis similares entre si.

De modo prático, verificou-se para a variedade Embrapa V122 e o híbrido triplo Agrobel 972 que as testemunhas sem capina (=grupo 1) apresentaram reduções de altura de planta, diâmetro do caule, diâmetro do capítulo e da produção de grãos em torno de 8,9-12,8; 29,7-30, 1 ; 30,0-32,6; e 51,4-29,3\%, respectivamente, em relação aos resultados das testemunhas capinadas de cada cultivar (=grupo 2). Entretanto, as médias das reduções dessas variáveis proporcionadas pelos tratamentos de herbicidas aplicados isoladamente e em misturas (=grupo 3) foram de apenas $3,8-5,2 ; 20,4-19,7 ; 7,9-8,4$; e $13,4-10,0 \%$, respectivamente, em comparação com as

Tabela 7 - Coeficientes de correlação entre as quatro variáveis analisadas no híbrido triplo Agrobel 972 e os dois primeiros componentes principais

\begin{tabular}{|c|l|c|c|}
\hline $\mathrm{N}^{0}$ & \multicolumn{1}{|c|}{ Variáveis } & $\mathrm{Y}_{1}$ & $\mathrm{Y}_{2}$ \\
\hline 1 & Altura de planta $(\mathrm{cm})$ & 0,981552 & $-0,013565$ \\
\hline 2 & Diâmetro do caule $(\mathrm{mm})$ & 0,901284 & 0,432096 \\
\hline 3 & Diâmetro do capítulo $(\mathrm{cm})$ & 0,964458 & $-0,244642$ \\
\hline 4 & Produtividade $\left(\mathrm{kg} \mathrm{ha}^{-1}\right)$ & 0,983526 & $-0,113787$ \\
\hline & \% Informação retida & 90,73 & 8,12 \\
\hline & \% Informação acumulada & 90,73 & 98,85 \\
\hline
\end{tabular}

Tabela 6 - Valores médios das quatro variáveis analisadas no híbrido triplo Agrobel 972, utilizadas na análise multivariada

\begin{tabular}{|l|c|c|c|c|c|}
\hline \multirow{2}{*}{ Tratamento } & Dose & $\begin{array}{c}\text { Altura da } \\
\text { planta }\end{array}$ & $\begin{array}{c}\text { Diâmetro do } \\
\text { caule }\end{array}$ & $\begin{array}{c}\text { Diâmetro do } \\
\text { capítulo }\end{array}$ & Produtividade \\
\cline { 2 - 6 } & $\left(\mathrm{g} \mathrm{ha}^{-1}\right)$ & $(\mathrm{cm})$ & $(\mathrm{mm})$ & $(\mathrm{cm})$ & $\left(\mathrm{kg} \mathrm{h}^{-1}\right)$ \\
\hline Testemunha sem capina & $\ldots .$. & 168,50 & 25,50 & 51,00 & $4.244,08$ \\
\hline Testemunha capinada & $\ldots .$. & 193,25 & 36,50 & 75,70 & $6.002,25$ \\
\hline oxadiazon & 250 & 183,75 & 29,25 & 70,25 & $5.534,91$ \\
\hline oxyfluorfen & 240 & 181,75 & 29,00 & 69,25 & $5.280,83$ \\
\hline S-metolachlor & 1440 & 182,75 & 29,25 & 69,00 & $5.309,58$ \\
\hline flumetsulam & 120 & 181,25 & 29,75 & 69,00 & $5.325,00$ \\
\hline pendimethalin & 1000 & 185,75 & 28,75 & 69,50 & $5.546,66$ \\
\hline oxyfluorfen + S-metolachlor & $192+960$ & 182,00 & 28,25 & 67,50 & $5.081,66$ \\
\hline flumetsulam + S-metolachlor & $72+960$ & 187,25 & 31,50 & 71,25 & $5.702,91$ \\
\hline pendimethalin + S-metolachlor & $1.000+1.440$ & 180,75 & 28,00 & 68,00 & $5.313,33$ \\
\hline pendimethalin + flumetsulam & $1.000+72$ & 183,00 & 30,00 & 70,25 & $5.515,16$ \\
\hline
\end{tabular}


testemunhas capinadas de cada cultivar (=grupo 2).

Ressalta-se que, apesar dos trabalhos realizados pelos pesquisadores Brighenti et al. (2000a, b, c, 2002), Vidal \& Fleck (2001), Fleck $\&$ Vidal (1994), Castro et al. (2002) e Concenço et al. (2007), ainda são escassas as informações referentes à seletividade de herbicidas na cultura do girassol, principalmente em condições de várzea, sendo necessária a realização de mais estudos que abordem esse assunto.

Com base nos resultados, pode-se concluir que os herbicidas aplicados isoladamente e em mistura apresentaram boa seletividade

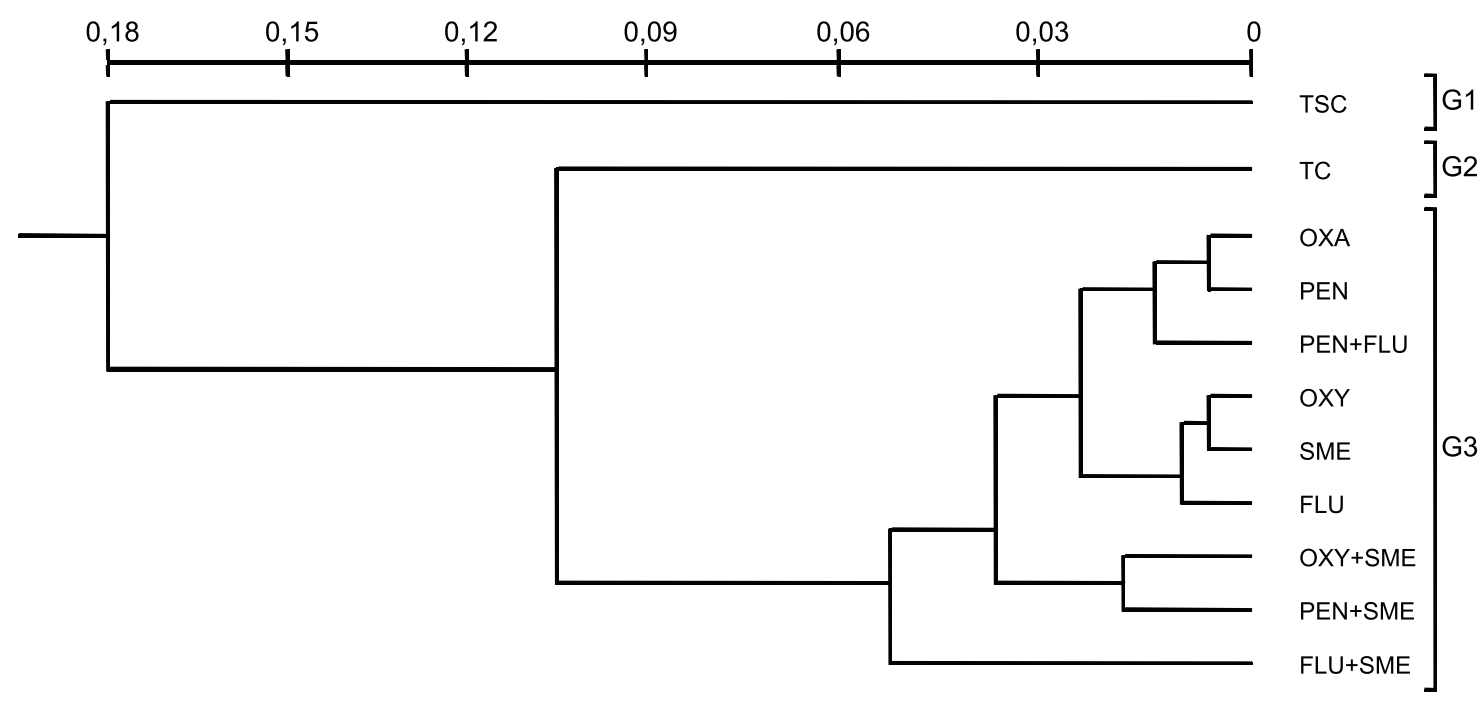

Figura 4 - Dendrograma resultante da análise de agrupamento dos tratamentos referentes ao híbrido triplo Agrobel 972, utilizandose a distância euclidiana média. $\mathrm{G} 1=$ grupo $1 ; \mathrm{G} 2=$ grupo $2 ; \mathrm{G} 3=$ grupo 3 ; TSC $=$ testemunha sem capina; TC $=$ testemunha capinada; OXA = oxadiazon; OXY = oxyfluorfen; SME = S-metolachlor; FLU = flumetsulam; PEN = pendimethalin; OXY+SME $=$ oxyfluorfen + S-metolachlor; FLU+SME $=$ flumetsulam + S-metolachlor; $\mathrm{PEN}+\mathrm{SME}=$ pendimethalin $+\mathrm{S}-\mathrm{metolachlor}$; $\mathrm{PEN}+\mathrm{FLU}=$ pendimethalin + flumetsulam .
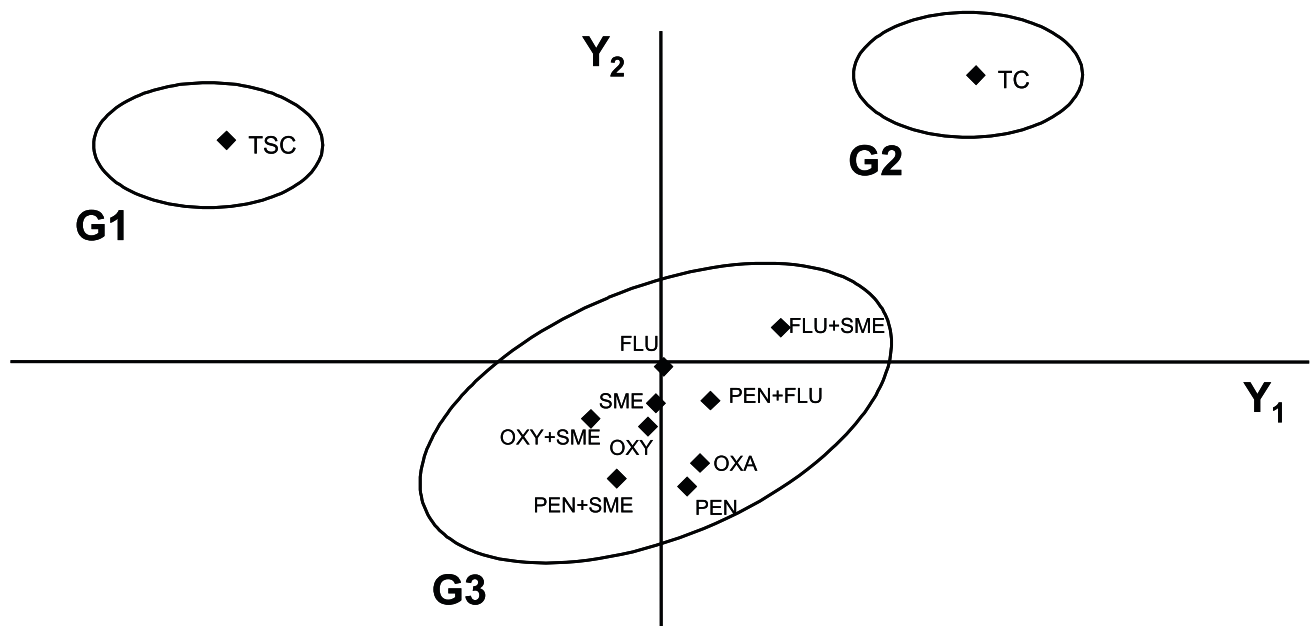

Figura 5 - Dispersão gráfica dos tratamentos referentes ao híbrido triplo Agrobel 972, utilizando-se os dois primeiros componentes principais $\left(\mathrm{Y}_{1}\right.$ e $\left.\mathrm{Y}_{2}\right)$. G1 = grupo $1 ; \mathrm{G} 2=$ grupo 2; G3 = grupo 3; TSC = testemunha sem capina; $\mathrm{TC}=$ testemunha capinada; $\mathrm{OXA}$ = oxadiazon; $\mathrm{OXY}=$ oxyfluorfen; $\mathrm{SME}=\mathrm{S}$-metolachlor; FLU = flumetsulam; $\mathrm{PEN}=$ pendimethalin; $\mathrm{OXY}+\mathrm{SME}=$ oxyfluorfen + S-metolachlor; FLU+SME $=$ flumetsulam + S-metolachlor; PEN+SME $=$ pendimethalin + S-metolachlor; PEN + FLU $=$ pendimethalin + flumetsulam. 
para a variedade de girassol Embrapa V122 e o híbrido triplo Agrobel 972, nas condições em que foram avaliados, uma vez que os efeitos provocados por esses tratamentos na altura de planta, no diâmetro do caule, no diâmetro do capítulo e na produção de grãos foram menos prejudiciais, em comparação aos efeitos da interferência das plantas daninhas.

\section{LITERATURA CITADA}

BLANCO, F. M. G.; VELINI, E. D. Persistência do herbicida sulfentrazone em solo cultivado com soja e seu efeito em culturas sucedâneas. Planta Daninha, v. 23, n. 4, p. 693-700, 2005.

BRIGHENTI, A. M. et al. Controle químico de plantas daninhas na cultura do girassol em solo de textura argilosa. $\mathbf{R}$. Bras. Herbic., v. 1, n. 1, p. 85-88, 2000a.

BRIGHENTI, A. M. et al. Seletividade de herbicidas aplicados em condições de pré-emergência na cultura do girassol. R. Bras. Herbic., v. 1, n. 3, p. 243-247, 2000 b.

BRIGHENTI, A. M. et al. Seletividade de herbicidas aplicados em pré-emergência na cultura do girassol em solo de textura argilosa. R. Bras. Herbic., v. 1, n. 2, p. 129-132, 2000c.

BRIGHENTI, A. M. et al. Persistência e fitotoxicidade do herbicida atrazine aplicado na cultura do milho sobre a cultura do girassol em sucessão. Planta Daninha, v. 20, n. 2, p. 291-297, 2002.

BRIGHENTI, A. M. et al. Cadastramento fitossociológico de plantas daninhas na cultura de girassol. Pesq. Agropec. Bras., v. 38, n. 5 , p. $651-657,2003$

BRIGHENTI, A. M. et al. Períodos de interferência de plantas daninhas na cultura do girassol. Planta Daninha, v. 22, n. 2 , p. $251-257,2004$

CASTRO, C.; BRIGHENTI, A. M.; OLIVEIRA JR., A. Mistura em tanque de boro e herbicidas em semeadura convencional de girassol. Planta Daninha, v. 20, n. 1, p. $83-91,2002$

CASTRO, C.; FARIAS, J. R. B. Ecofisiologia do girassol. In: LEITE, R. M. V. B. C.; BRIGHENTI, A. M.; CASTRO, C. Girassol no Brasil. Londrina: Embrapa/CNPSo, 2005. p. $163-218$

CONCENÇO, G. et al. Sulfentrazone e a qualidade fisiológica das sementes de girassol. R. Bras. Agroci., v. 13, n. 1, p. 109-113, 2007.

DAMALAS, C. A.; ELEFTHEROHORINOS, I. G. Dicamba and atrazine antagonism on sulfonylurea herbicides used for Johnsongrass (Sorghum halepense) control in corn (Zea mays). Weed Technol., v. 15, n. 1, p. 62-67, 2001.
EMPRESA BRASILEIRA DE PESQUISA

AGROPECUÁRIA - EMBRAPA. Centro nacional de pesquisa de solos. Sistema brasileiro de classificação de solos. Brasília: Embrapa Produção de Informação; Rio de Janeiro: Embrapa Solos, 1999. 412 p.

FELIPE, J. M.; MARTINS, D.; COSTA, N. V. Seletividade de herbicidas aplicados em pré-emergência sobre cultivares de batata. Bragantia, v. 65, n. 4, p. 615-621, 2006

FLECK, N. G.; VIDAL, R. A. Injúria potencial de herbicidas de solo ao girassol. III - imazaquin e imazethapyr.

Planta Daninha, v. 12, n. 1, p. 39-43, 1994.

PELÚZIO, J. M. et al. Comportamento de cultivares de soja sob condições de várzea irrigada no sul do estado do tocantins, entressafra 2005. Biosci. J., v. 24, n. 1, p. 75-80, 2008 .

PITELLI, R. A. Interferência de plantas daninhas em culturas agrícolas. Inf. Agropec., v. 11, n. 129, p. 16-17, 1985

PROCÓPIO, S. O. et al. Tolerância de cultivares de feijão ao S-metolachlor em diferentes condições de aplicação

Planta Daninha, v. 19, n. 2, p. 263-271, 2001.

RODRIGUES, R. B.; ALMEIDA, F. S. Guia de herbicidas. 5.ed. Londrina: 2005. 592 p.

ROHLF, F. J. Adaptative hierarchical clustering schemes System. Zool., v. 19, n. 1, p. 58-82, 1970.

SOCIEDADE BRASILEIRA DA CIÊNCIA DAS PLANTAS DANINHAS - SBCPD. Procedimentos para instalação, avaliação e análise de experimentos com herbicidas. Londrina: $1995.42 \mathrm{p}$.

SOUZA, A. P. et al. Efeito do oxyfluorfen, 2, 4-d e glyphosate na ativ idade microbiana de solos com diferentes texturas e conteúdos de matéria orgânica. Planta Daninha, v. 14 , n. 1, p. 55-64, 1996.

STOUGAARD, R. N.; SHEA, P. J.; MARTIN, A. R. Effect of soil type and $\mathrm{pH}$ on adsorption, mobility and efficacy of imazaquin and imazethapyr. Weed Sci., v. 36, n. 1, p. 67-73, 1990.

SNEATH, P. H. A.; SOKAL, R. R. Numerical taxonomy San Francisco: W. H. Freemam, 1973. 573 p.

VANGESSEL, M. J.; AYENI, A. O.; MAJEK, B. A. Optimum glyphosate timing with or without residual herbicides in glyphosate-resistant soybeans (Glycine max) under full-season conventional tillage. Weed Technol., v. 14, n. 1, p. 140-149, 2000.

VIDAL, R. A.; FLECK, N. G. Injúria potencial de herbicidas de solo ao girassol. IV - rendimento de aquênios e componentes do rendimento. Planta Daninha, v. 12, n. 1, p. 44-51, 1994. 